\title{
KEANEKARAGAMAN DAN DOMINASI GULMA PADA PERTANAMAN PADI (Oryza sativa L.) KONVENSIONAL DAN ORGANIK DI KECAMATAN CISOMPET KABUPATEN GARUT
}

\section{THE DIVERSITY AND DOMINANCE OF WEEDS IN RICE CULTIVATION (Oryza sativa L.) CONVENTIONAL AND ORGANIC IN CISOMPET OF GARUT}

\author{
Asep Rohimat, Jenal Mutakin, Hanny Hidayati Nafi'ah \\ Fakultas Pertanian Universitas Garut \\ E-mail :hanny.hidayati@uniga.ac.id
}

\begin{abstract}
ABSTRAK
Padi merupakan jenis tanaman pangan yang sangat penting, karena merupakan sumber makanan pokok. Penelitian ini bertujuan untuk mengetahui keanekaragaman dan dominasi gulma pada pertanaman padi konvensional dan organik di Kecamatan Cisompet Kabupaten Garut. Penelitian dilaksanakan pada Bulan Juni sampai Agustus 2017. Metode yang digunakan dalam penelitian ini adalah non eksperimental melalui metode survey. Pengambilan sampel dilakukan pada 3 areal yang berbeda dengan luas plot masing-masing 50 x $50 \mathrm{~cm}$. Setiap areal terdapat 5 plot. Hasil penelitian menunjukan terdapat keanekaragaman gulma. Tercatat 7 jenis gulma ditemukan di pertanaman padi konvensional dan 6 jenis gulma ditemukan di pertanaman padi organik. Jenis gulma yang dominan pada pertanaman padi konvensional adalah Echinochloa Crus-galli, Monochoria vaginalis, Limonocharis flave, dan Plantago major. Tercatat jenis gulma yang dominan pada pertanaman padi organik adalah Azolla pinnata, Pistia stratiodes, Salvinia molesta, Echinochloa Crus-galli, dan Fimbristylis miliaceae.
\end{abstract}

Kata Kunci : Keanekaragaman, Gulma, Padi Organik, Padi Konvensional

\begin{abstract}
Rice is a very important food crop, because it is the main food source. This study aims to determine the diversity and dominance of weeds in conventional and organic rice cultivation in Cisompet of Garut. The study was conducted from June to August 2017. The method used in this research is non experimental
\end{abstract}


through survey method. Sampling was perfomed in three different areas with the area of each $50 \mathrm{~cm} \times 50 \mathrm{~cm}$. There are five plot in each area. The results showed that weed diversity. Recorded 7 types of weeds found in conventional rice crops and 6 species of weeds found in organic rice cultivation. The dominant types of weeds in conventional rice crops are Echinochloa Crus- galli, Monochoria vaginalis, Limonocharis flave, and Plantago major. Recorded species of dominant weeds in organic rice crops are Azolla pinnata, Pistia stratiodes, Salvinia molesta, Echinochloa Crus-galli, and Fimbristylis miliaceae. Keywords : Diversity, Weeds, Organic Rice, Conventional Rice.

\section{PENDAHULUAN}

Padi (Oryza sativa L.) Padi (Oryza sativa L.) merupakan tanaman pangan penting di Indonesia, karena lebih dari setengah penduduk Indonesia menjadikan beras sebagai makanan pokok. Beras memenuhi sekitar $45 \%$ dari total "food intake" atau sekitar $80 \%$ sumber karbohidrat utama dalam pola konsumsi masyarakat. Peningkatan jumlah penduduk Indonesia setiap tahunnya berdampak pada peningkatan kebutuhan pangan terutama beras. (Nurmalina, 2007). Salah satu faktor yang menyebabkan rendahnya produksi dan produktivitas padi adalah gangguan gulma. Penurunan hasil padi akibat gulma secara nasional mencapai 15-42 \% untuk padi sawah dan padi gogo 47-87 \% (Pitoyo, 2006). Gulma yang umum terdapat pada pertanaman padi sawah adalah Monochoria vaginalis, Marsilea crenata, Cyperus difformis, Paspalum distichum, Echinochloa crus-galli dan Leptochloa chinensis (Tjitrosemito, 1994).

Gulma tidak selalu merugikan tanaman, pada tingkat populasi atau periode tertentu tidak berpengaruh atau berpengaruh sedikit pada tanaman sehingga gulma yang tumbuh pada periode itu tidak perlu dikendalikan. Oleh karena itu cara budidaya, jenis dan kerapatan gulma akan sangat menentukan saat penyiangan gulma. Komposisi gulma akan beragam pada tanaman yang mempunyai ketinggian tempat yang berbeda. Hasil penelitian dikawasan Sumatera Utara dan Aceh, pada kebun karet yang terletak pada ketinggian 0 sampai 30 mdpl dijumpai lebih dominan jenis gulma dari golongan teki-tekian, sedangkan pada kebun yang terletak 30 sampai 100 mdpl dijumpai lebih dominan jenis rumput-rumputan (Nasution, 1984).

Jenis tanah, pola tanam dan jenis tanaman yang dibudidayakan memengaruhi jumlah dan keanekaragaman jenis gulma (Knott, 2002). Spesies gulma juga dipengaruhi oleh kerapatan tanaman, kesuburan tanah, pola budidaya dan pengolahan tanah (Aldrich, 1984). Pengelolaan gulma dapat dilaksanakan lebih baik apabila terlebih dahulu diketahui tingkat dominasi gulma pada tanaman padi. Oleh karena itu, penelitian ini bertujuan untuk mempelajari keragaman dan 
dominasi gulma pada pertanaman padi (Oryza sativa L.) secara konvensional dan organik di Kecamatan Cisompet Kabupaten Garut.

\section{BAHAN DAN METODE}

Percobaan dilaksanakan di areal pertanaman padi milik petani di Kecamatan Cisomepet, Kabupaten Garut. Sampel yang tersebar di tiga Desa, yaitu Desa Panyindangan, Desa Sukanagara, dan Desa Cisompet.

\section{Bahan dan Alat Percobaan}

Bahan yang digunakan pada percobaan ini adalah vegetasi pada tanaman padi konvensional dan organik di tiga areal pertanaman padi serta kuisioner bahan penelitian. Alat-alat yang digunakan selama percobaan ini adalah frame 50 x 50 $\mathrm{cm}$, gunting, penggaris, buku catatan, pensil/pulpen, amplop, plastik, timbangan elektrik, oven, dan kamera.

\section{Metode Penelitian}

Metode yang digunakan dalam penelitian adalah non eksperimental secara kualitatif (weed survey) dan kuantitatif (identifikasi). Setiap lokasi sampel dilakukan analisis vegetasi gulma secara diagonal (5 kali) untuk setiap luasan lahan pertanaman padi konvensional dan organik dengan metode kuadrat, ukuran yang digunakan $50 \mathrm{~cm} \times 50 \mathrm{~cm}$. Pada setiap desa terpilih diambil contoh gulma pada lokasi pertanaman padi konvensional dan organik. Setiap spesies gulma yang terdapat pada petak kuadrat diidentifikasi berdasarkan spesies, kemudian dihitung jumlahnya dan ditimbang bobot keringnya. Jenis gulma yang diinventarisir akan ditampilkan dalam bentuk deskriptif. Data yang diperoleh dari hasil penentuan frame digunakan untuk menghitung Tingkat Keanekaragaman Gulma dengan terlebih dahulu menentukan Nilai Penting dan Indeks Keanekaragaman, sedangkan untuk menghitung Dominasi Gulma terlebih dahulu menentukan Bobot Kering dan Summed Dominance Ratio (SDR) dengan formula sebagai berikut :

a) Nilai Penting Gulma (NP) adalah nilai yang diperoleh dari perhitungan sebagaimana dikemukakan oleh Chaves dan Bhandari (1982), yaitu :

$$
\text { Kerapatan relatif }=\frac{\text { Nilai kerapatan mutlak suatu jenis }}{\sum \text { Nilai kerapatan mutlak seluruh jenis }} \times 100 \%
$$

Frekuensi relatif $=\underline{\text { Nilai frekuensi mutlak suatu jenis }} \times 100 \%$


Dominasi relatif $=$ Nilai dominasi mutlak suatu jenis $\times 100 \%$

$\sum$ Nilai dominasi mutlak seluruh jenis

Kerapatan mutlak $=\sum$ individu jenis gulma tertentu dalam petak

Frekuensi mutlak $=\sum$ plot ditemukan suatu jenis

$\sum$ seluruh plot pengamatan

Dominasi mutlak $=\underline{\text { Bobot Kering }}$

Luas Plot

b) Indeks Keanekaragaman Shannon - Wiener (Indeks Diversitas). Indeks keanekaragama Shannon - Wiener yang digunakan memiliki formula sebagai berikut : $\mathrm{H}^{\prime}=-\sum$ (pi) (ln pi).

Keterangan :

H' = Indeks Keanekaragaman

pi = Perbandingan jumlah nilai penting suatu jenis dengan jumlah nilai penting seluruh jenis $(\mathrm{ni} / \mathrm{N})$.

Kriteria : Nilai Indeks Keanekaragaman antara 0 - 2 (rendah) Nilai Indeks Keanekaragaman antara 2 - 3 (sedang) Nilai Indeks Keanekaragaman antara > 3 (tinggi)

c) Summed Dominance Ratio (SDR) adalah parameter yang digunakan untuk menyatakan tingkat dominasi spesies-spesies gulma dalam suatu komunitas. Summed Dominance Ratio (SDR) memiliki formula sebagai berikut :

$\mathrm{SDR}=\underline{\text { Nilai Penting }}$

3

\section{HASIL DAN PEMBAHASAN}

Hasil pengamatan tercatat ditemukan 10 jenis gulma padi sawah yaitu Azzola pinnata, Pistia stratiodes, Salvinia molesta, Echinocloa crus-galli, Fimbristylis miliaceae, Monochoria vaginalis, Limonocharis flave, Oxalis corniculata L., dan Marsilea clover. Nilai penting gulma disajikan pada Tabel 1. Data tersebut diperlukan untuk menghitung Indeks Keanekaragaman Gulma. 
Tercatat 7 jenis gulma yaitu Echinochloa crus-galli, Fimbristylis miliaceae, Monochoria vaginalis, Limonocharis flave, Oxalis corniculata L., Marsilea clover, dan Plantago major. Total individu jenis gulma yang ditemukan adalah 350. Data pada Tabel 1 juga menunjukan bahwa pada pertanaman padi organik tercatat 6 jenis gulma yang ditemukan yaitu Azzola pinnata, Pistia stratiodes, Salvinia molesta, Echinochloa crus-galli, Fimbristylis miliaceae, dan Limonocharis flave. Total individu jenis gulma yang ditemukan adalah 676. Tercatat ada 3 jenis gulma yang ditemukan di kedua areal pertanaman padi, baik pada areal konvensional maupun pada areal organik yaitu Echinochloa crus-galli, Fimbristylis miliaceae, dan Limonocharis flave.

Tabel 1. Nilai Penting Gulma pada Pertanaman Padi Konvensional dan Organik di Kecamatan Cisompet Kabupaten Garut

\begin{tabular}{|c|l|l|c|c|}
\hline \multirow{2}{*}{ No. } & \multirow{2}{*}{ Gulma } & \multirow{2}{*}{ Nama Lokal } & \multicolumn{2}{c|}{ Nilai Penting (\%) } \\
\cline { 4 - 5 } & & & Konvensional & Organik \\
\hline 1 & Azolla pinnata & Kareo & - & 32,42 \\
\hline 2 & Pistia stratiodes & Kiapu & - & 44,09 \\
\hline 3 & Salvinia molesta & Kiambang & - & 42,58 \\
\hline 4 & Echinocloa crus-galli & Jawan & 37,06 & 110,41 \\
\hline 5 & Fimbristylis miliaceae & $\begin{array}{l}\text { Panon } \\
\text { Munding }\end{array}$ & 10,66 & 59,61 \\
\hline 6 & Monochoria vaginalis & Wewehan & 82,09 & - \\
\hline 7 & Limonocharis flave & Genjer & 44,55 & 10,89 \\
\hline 8 & Oxalis corniculata L. & Cacalincingan & 13,13 & - \\
\hline 9 & Marsilea clover & Semanggi & 42,89 & - \\
\hline 10 & Plantago major & Daun Sendok & 69,63 & - \\
\hline \multicolumn{2}{|l}{ Total $\sum$ jenis } & 7 & 6 \\
\hline \multicolumn{2}{|l}{ Total $\sum$ Individu Jenis } & 350 & 676 \\
\hline \multicolumn{2}{|l}{ Total $\sum$ Indeks Keanekaragaman Jenis } & 0,77 & 0,70 \\
\hline
\end{tabular}

Indeks Keanekaragaman (H') Shannon - Wiener diperoleh dengan parameter kemelimpahan jenis dan proporsi kemelimpahan masing-masing jenis. Kriteria yang digunakan untuk menafsirkan formula tersebut adalah apabila nilai Indeks Keanekaragaman (H') antara 0 - 2 (rendah), 2 - 3 (sedang), dan > 3 (tinggi). Data pada Tabel 2 menunjukan hasil pengamatan pada areal pertanaman padi konvensional menunjukkan nilai indeks keanekaragaman yang diperoleh adalah 0,77. Angka tersebut menunjukkan bahwa tingkat keanekaragaman jenis di areal pengamatan termasuk kategori rendah. Dari hasil pengamatan pada areal pertanaman padi organik menunjukkan nilai indeks keanekaragaman yang diperoleh adalah 0,70. Angka tersebut menunjukkan bahwa tingkat keanekaragaman jenis di areal pengamatan termasuk kategori rendah. 
Tabel 2. Indeks Keanekaragaman Gulma pada Pertanaman Padi Konvensional dan Organik di Kecamatan Cisompet Kabupaten Garut

\begin{tabular}{|c|l|l|c|c|}
\hline \multirow{2}{*}{ No. } & \multicolumn{1}{|c|}{ Gulma } & \multirow{2}{*}{ Nama Lokal } & \multicolumn{2}{c|}{ Indeks Keanekaragama (H') } \\
\cline { 4 - 5 } & & & Konvensional & Organik \\
\hline 1 & Azolla pinnata & Kareo & - & 0,10 \\
\hline 2 & Pistia stratiodes & Kiapu & - & 0,12 \\
\hline 3 & Salvinia molesta & Kiambang & - & 0,12 \\
\hline 4 & Echinocloa crus-galli & Jawan & 0,11 & 0,16 \\
\hline 5 & Fimbristylis miliaceae & $\begin{array}{l}\text { Panon } \\
\text { Munding }\end{array}$ & 0,05 & 0,14 \\
\hline 6 & Monochoria vaginalis & Wewehan & 0,15 & - \\
\hline 7 & Limonocharis flave & Genjer & 0,12 & 0,05 \\
\hline 8 & Oxalis corniculata L. & Cacalincingan & 0,06 & - \\
\hline 9 & Marsilea clover & Semanggi & 0,12 & - \\
\hline 10 & Plantago major & Daun Sendok & 0,15 & - \\
\hline & & 0,77 & 0,70 \\
\hline
\end{tabular}

Keterangan : Kriteria $0-2$ (rendah), $2-3$ (sedang), > 3 (tinggi)

Analisis data terhadap bobot kering gulma disajikan pada Tabel 3. Data tersebut diperlukan untuk menghitung Dominasi Gulma. Diketahui bahwa gulma jenis Echinochloa crus-galli memiliki bobot kering tertinggi pada pertanaman padi konvensional dengan bobot kering sebesar 16,20 gram. Data yang sama ditunjukan pada areal pertanaman padi organik bahwa gulma jenis Echinochloa crus-galli memiliki bobot kering tertinggi yaitu sebesar 149, 80 gram.

Tabel 3. Bobot Kering Gulma Per Spesies Dan Total pada Pertanaman Padi Konvensional dan Organik di Kecamatan Cisompet Kabupaten Garut

\begin{tabular}{|c|l|l|c|c|}
\hline \multirow{2}{*}{ No. } & \multirow{2}{*}{ Gulma } & \multirow{2}{*}{ Nama Lokal } & \multicolumn{2}{c|}{ Bobot Kering (gr) } \\
\cline { 4 - 5 } & & & Konvensional & Organik \\
\hline 1 & Azolla pinnata & Kareo & - & 4,50 \\
\hline 2 & Pistia stratiodes & Kiapu & - & 12,10 \\
\hline 3 & Salvinia molesta & Kiambang & - & 14,90 \\
\hline 4 & Echinocloa crus-galli & Jawan & $16,20^{*}$ & $149,80^{*}$ \\
\hline 5 & Fimbristylis miliaceae & $\begin{array}{l}\text { Panon } \\
\text { Munding }\end{array}$ & 3,70 & 48,40 \\
\hline 6 & Monochoria vaginalis & Wewehan & 13,50 & - \\
\hline 7 & Limonocharis flave & Genjer & 6,50 & 2,50 \\
\hline 8 & Oxalis corniculata L. & Cacalincingan & 4,00 & - \\
\hline 9 & Marsilea clover & Semanggi & 6,90 & - \\
\hline 10 & Plantago major & Daun Sendok & 13,20 & - \\
\hline Total & & & 64,00 & 232,20 \\
\hline
\end{tabular}

Keterangan $: *$ bobot kering tertinggi 
Hasil analisis Dominasi Gulma atau Summed Dominance Ratio (SDR) disajikan pada Tabel 4. Tercatat bahwa jenis yang mendominasi terdapat 5 jenis, yaitu : Echinochloa crus-galli (12,35 \%), Monochoria vaginalis (27,36 \%), Limonocharis flave (14,85\%), Marsilea clover (14,30\%), dan Plantago major $(23,21 \%)$. Nilai persentase SDR tertinggi adalah jenis Monochoria vaginalis dengan nilai SDR 23,36 \%. vaginalis, Marselia clover, Echinochloa crus -galli, dan Leptochloa chinensis. Sementara pada pertanaman padi organik gulma yang mendominasi terdapat 5 jenis, yaitu : Azolla pinnata (10, $81 \%)$, Pistia stratiodes $(14,70 \%)$, Salvinia molesta $(14,15 \%)$, Echinochloa crus-galli $(36,80 \%)$, dan Fimbristylis miliaceae $(19,87 \%)$. Berdasarkan data pada tabel 3 nilai gulma dominan pada pertanaman padi organik adalah jenis Echinochloa crus-galli dengan nilai SDR 36,80 \%, sedangkan gulma Limonocharis flave memiliki nilai SDR terendah yaitu 3,63 \%. Jenis gulma Fimbristylis miliaceae menempati urutan kedua dari spesies gulma yang mendominasi pada pertanaman padi organik dengan nilai SDR 19,87\%.

\section{Tabel 4. Nilai Summed Dominance Ratio (SDR) Gulma Pada Pertanaman Padi Konvensional dan Organik di Kecamatan Cisompet Kabupaten Garut}

\begin{tabular}{|c|c|c|c|c|}
\hline \multirow{2}{*}{ No. } & \multirow{2}{*}{ Gulma } & \multirow{2}{*}{ Nama Lokal } & \multicolumn{2}{|c|}{ SDR (\%) } \\
\hline & & & Konvensional & Organik \\
\hline 1 & Azolla pinnata & Kareo & - & $10,81^{*}$ \\
\hline 2 & Pistia stratiodes & Kiapu & - & $14,70^{*}$ \\
\hline 3 & Salvinia molesta & Kiambang & - & $14,15^{*}$ \\
\hline 4 & Echinocloa crus-galli & Jawan & $12,35^{*}$ & $36,80^{*}$ \\
\hline 5 & Fimbristylis miliaceae & $\begin{array}{l}\text { Panon } \\
\text { Munding }\end{array}$ & 3,55 & $19,87 *$ \\
\hline 6 & Monochoria vaginalis & Wewehan & $27,36^{*}$ & - \\
\hline 7 & Limonocharis flave & Genjer & $14,85^{*}$ & 3,63 \\
\hline 8 & Oxalis corniculata $L$. & Cacalincingan & 4,38 & - \\
\hline 9 & Marsilea clover & Semanggi & $14,30 *$ & - \\
\hline 10 & Plantago major & Daun Sendok & $23,21 *$ & - \\
\hline
\end{tabular}

Keterangan : * = Gulma yang dominan pada pertanaman padi konvensional dan organik di dataran rendah Kabupaten Garut (jika persentasenya diatas $10 \%$ ).

\section{KESIMPULAN}

Tingkat keanekaragaman gulma pada pertanaman padi konvensional di Kecamatan Cisompet Kabupaten Garut termasuk kategori rendah dengan nilai Indeks Keanekaragaman (H') sebesar 0,77 dan ditemukan sebanyak 7 jenis gulma. Gulma yang ditemukan di areal pertanaman padi organik sebanyak 6 jenis dengan 
Indeks Keanekaragaman sebesar 0,70 (kategori rendah). Terdapat gulma dominan pada pertanaman padi konvensional yaitu Echinochloa crus-galli (12,35 \%), Monochoria vaginalis (27,36 \%), Limonocharis flave (14,85\%), Marsilea clover (14,30\%), dan Plantago major (23,21 \%). Terdapat gulma dominan pada pertanaman padi organik yaitu Azolla pinnata (10, $81 \%)$, Pistia stratiodes (14,70 $\%)$, Salvinia molesta $(14,15 \%)$, Echinochloa crus-galli $(36,80 \%)$, dan Fimbristylis miliaceae $(19,87 \%)$.

\section{DAFTAR PUSTAKA}

Aldrich, R. J. 1984. Weed Crop Ecology Principles in Weed Management. Wadsworth, Inc., Belmont, California, USA. p : 92-126 ; 210-244.

Knott, C.M. 2002. Weed control in other arable and field vegetable crops, p.359398. In R.E.L. Naylor (ed.) Weed management handbook. 9th ed. Blackwell Science, Ltd.,Oxford, UK.

Nasution. 1984. Gulma dan Pengendaliannya di Perkebunan Karet Sumatera Utara dan dan Aceh. Pusat Penelitian dan Pengembangan Perkebunan Tanjung Marowa (P4TM). Fakultas Pertanian Universitas Gajah Mada. Yogyakarta.

Nurmalina R. 2007. Akibat Konversi Tanah, Produksi Beras 2010. Terancam Defisit 12 Juta Ton. www.gatra.com. Diakses 15 Oktober 2017.

Pitoyo. 2006. Mesin Penyiang Gulma Padi Sawah. http//www.litbangdeptan.go.id. Diakses pada tanggal 14 Mei 2017.

Tjitrosemito, S. 1994. Integrated management of paddy and aquatic weeds in Indonesia, p. 20-31. Proceedings of the International Seminar Biological Control and Integrated Management of Paddy and Aquatic Weeds in Asia. Japan, Oktober, 19-25. 